\title{
Arctic climate change: observed and modelled temperature and sea-ice variability
}

\author{
By O.M. JOHANNESSEN*, L. BENGTSSON, M.W. MILES, S.I. KUZMINA, \\ V.A. SEMENOV, G.V. ALEKSEEV, A.P. NAGURNYI, V.F. ZAKHAROV, L.P. BOBYLEV, \\ L.H. PETTERSSON, K. HASSELMANN and H.P. CATTLE, Tellus 56A, 328-341
}

We have noted a few errors, primarily regarding colour reproduction and transposed references to multi-panel figures, in our paper, which was published in August 2004.

1. Section 2: The units for the colour bar scales in Figs. 1 and 2 are ${ }^{\circ} \mathrm{C}$.

2. Section 3: Fig. 5 should appear in colour as below:

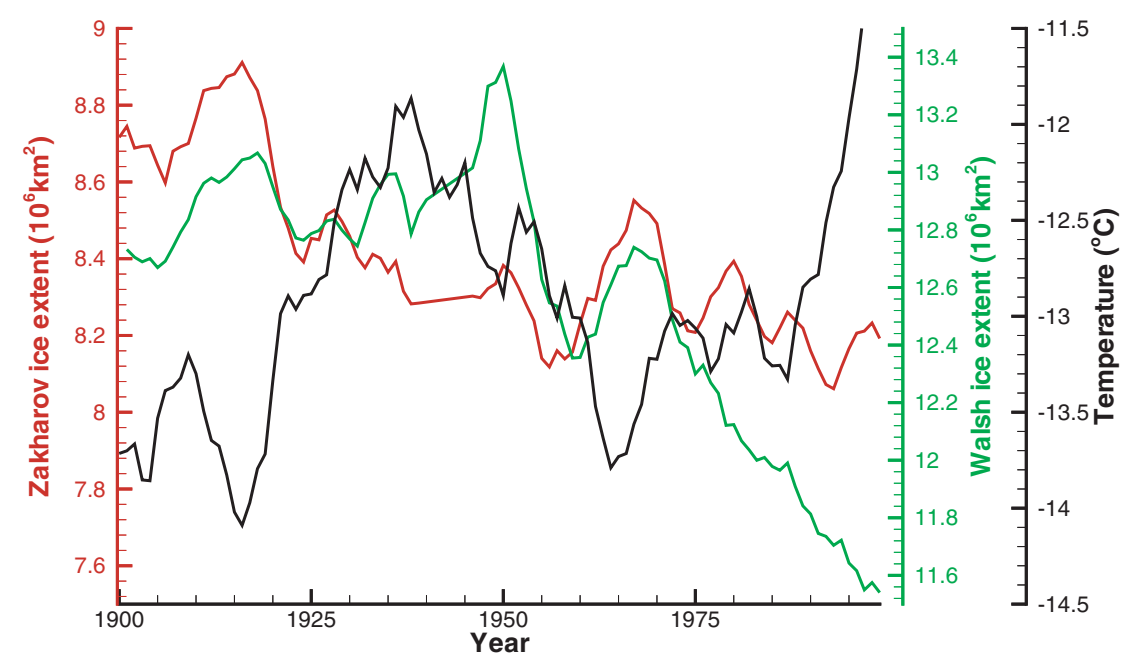

Fig 5. Annual sea-ice extent (area within the ice-ocean margin) derived from a new "Zakharov" sea-ice dataset (red), Northern Hemisphere sea-ice extent from the widely used "Walsh" dataset (green) and zonal $\left(70-90^{\circ} \mathrm{N}\right)$ mean annual surface air temperature (SAT) (black) since 1900. The time series shown are 5 -year running means.

3. Section 4. The fourth sentence in the third paragraph should read: Results from the B2 experiments are shown in Fig. 9, which depicts decadal averages of winter (Fig. 9a and c) and summer (Fig. 9b and d) sea-ice concentrations in 2001-2010 and 20812090 .

4. Section 4. The first sentence in the Fig. 8 caption should read: ECHAM4-modelled Northern Hemisphere sea-ice concentration in late winter (March) from (a) 2001-2010 and (c) 2081-2090, and in late summer (September) from (b) 2001-2010 and (d) 20812090 .

5. Section 4. The first sentence in the Fig. 9 caption should read: HadCM3-modelled Northern Hemisphere sea-ice concentration in late winter (March) from (a) 2001-2010 and (c) 2081-2090, and in late summer (September) from (b) 2001-2010 and (d) 20812090 .

\footnotetext{
* Corresponding author.

Nansen Environmental and Remote Sensing Center, N-5006 Bergen, Norway

e-mail: ola.johannessen@nersc.no
} 
6. Section 4: Fig. 9 should appear in colour as below:

2001-2010

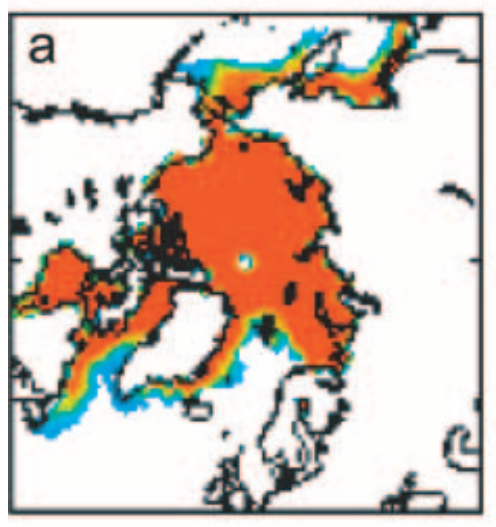

$2081-2090$

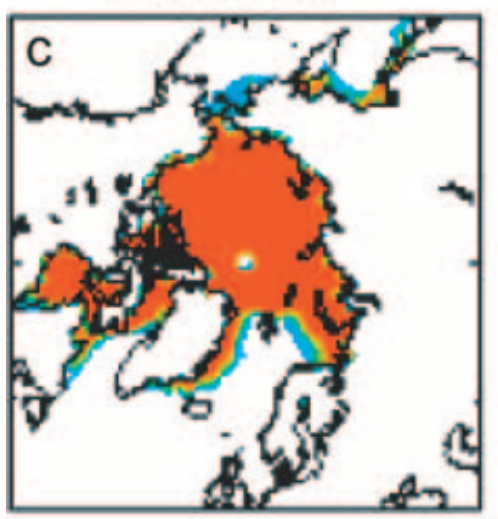

2001-2010

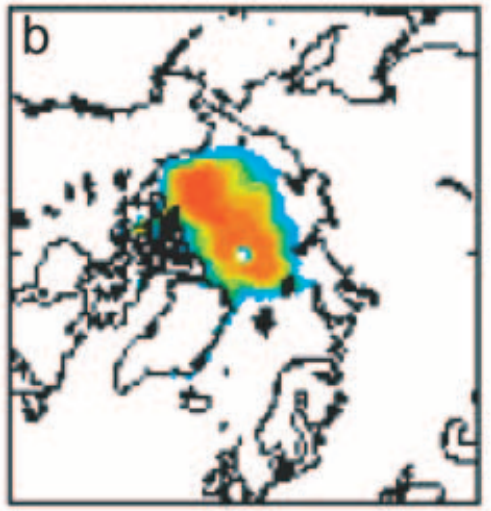

$2081-2090$

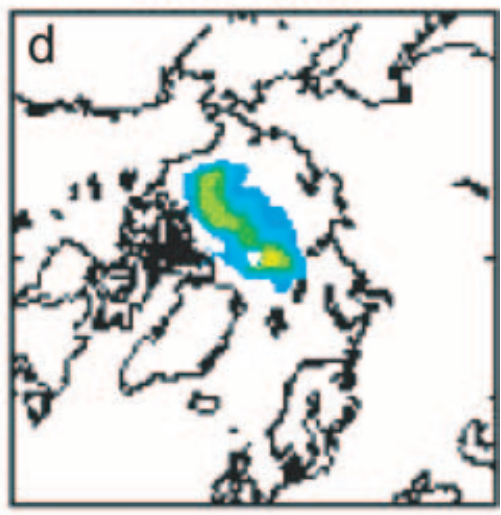

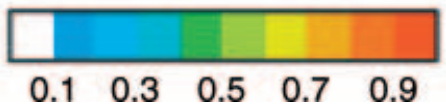

Fig 9. HadCm3-modelled Northern Hemisphere sea-ice concentration in late winter (March) from (a) 2001-2010 and (c) 2081-2090, and in late summer (September) from (b) 2001-2010 and (d) 2081-2090. The model has been run using IPCC SRES emissions scenarios A2 and B2, the latter (shown) being a "medium-low" estimate.

7. The following reference list entries should be:

Johannessen O. M., Shalina, E., Kuzmina, S., Miles, M. W. and Nagurnyi, A. 2001. Shrinking of the Arctic sea ice cover over the last decades. In Smith, W. L. and Timofeyev, Y. M. (eds.) Proc. Intl. Radiation Sympos., St. Petersburg, Russia. 24-29 July 2000, Deepak Publishing, Hampton, USA, 1007-1011.

Johannessen, O. M., Shalina, E. V. and Miles, M. W. 1999. Satellite evidence for an Arctic sea ice cover in transformation. Science 286, $1937-1939$. 